\title{
Lived Experiences of First Time Baccalaureate Nursing Students in the Clinical Practice
}

\author{
Maria Jocelyn B. Natividad ${ }^{1}$, Ibtehal I. Qazanli ${ }^{2} \&$ Khalid A. Aljohani ${ }^{3}$ \\ ${ }^{1}$ Medical Surgical Department-College of Nursing, Taibah University, Madinah, Saudi Arabia \\ ${ }^{2}$ Community Health Nursing-Nursing Administration Department, Ministry of Health, Madinah, Saudi Arabia \\ ${ }^{3}$ Community Health Department - College of Nursing, Taibah University, Madinah, Saudi Arabia \\ Correspondence: Khalid A. Aljohani, Community Health Department-College of Nursing, Taibah University, \\ Madinah, Saudi Arabia. Tel: 966-555-313-015.
}

Received: July 14, 2020 Accepted: October 30, 2020 Online Published: November 11, 2020

doi:10.5539/gjhs.v12n13p86 URL: https://doi.org/10.5539/gihs.v12n13p86

\begin{abstract}
Introduction: Nursing students' first clinical exposure may raise anxiety as they question their ability and experienced a lack of confidence as they adjust themselves in the clinical learning environment.
\end{abstract}

Aim: To explore the lived experiences of first-time Baccalaureate nursing students in the clinical area.

Methods: A phenomenological qualitative research design was utilized where 18 Baccalaureate nursing students were individually interviewed. Data were analyzed using the seven steps of Collaizi's method.

Result: Three main themes that emerged were clinical practice on the first-hand look; uncertainties in a new learning environment; and nursing as a life-changing experience. Subthemes were recorded and explained in the research report.

Conclusion: Nursing students who had their first-ever exposure to clinical practice had various experiences both positive and negative. The Nursing College must emphasize comprehensive orientation before students' exposure to clinical practice.

Keywords: clinical practice, lived experience, nursing student, Saudi Arabia

\section{Introduction}

Beginning a professional program is the hallmark that an individual is starting to build a future career. Nonetheless, starting on professional education can be crucial and challenging. Becoming a nurse requires courage and it is unique from the varieties of professions because it is not only focused on the acquisition of higher-order thinking and technical abilities but most importantly the development of human skills such as caring, compassion, and empathy which commonly acquired during clinical practice.

On the journey towards the attainment of the nursing profession, struggles may be experienced such as stress, depression, and anxiety, which can hinder learning and ruin clinical practice performance (Turner \& McCarthy, 2017). Though clinical learning experience enhances the nursing skills, it may also bring out challenges, difficulties, and anxiety to the students (Baraz, Memarian, \& Vanaki, 2015), and as stress arises it can affect their mental health (Galvin, Suominen, Morgan, O'Connell, \& Smith, 2015). Students' anxiety rises during their first clinical exposure which as they may question their ability and experienced a lack of confidence as they adjust themselves in the clinical learning environment. Likewise, establishing rapport and gaining the trust of their patients was not easy for them (Sun et al., 2016). Hence, understanding students' anxiety and experiences and preparing them for their initial clinical exposure must be given an important emphasis by the nurse educators. Assisting students on their first clinical duty proactively help them to reduce their possible anxiety. On the other hand, 'academic demands such as paper works, interaction with others in the clinical environment, and caring for patients and families were the perceived stressors among Saudi nursing students (Al-Zayyat \& Al-Gamal, 2014).

Nursing students' first clinical exposure can be a crucial and significant period in their educational journey. That is why it is relevant to understand the students' viewpoints and feelings during their initial clinical practice as they may experience anxiousness, fear, and self-doubt. These are most commonly observed in nursing students in their real-life experience during first clinical exposure. This can be seen during their interaction with the patients, 
collaboration with other health care providers, and when performing interventions as part of their nursing care. With this, the researchers perceived it beneficial to explore the lived experiences of students who have their first clinical exposure since the aim of the clinical learning experience is to prepare the students to learn and become better as they progress with the Nursing program. By this means, preparing students in the clinical practice requires understanding that they may face challenges in this learning environment, hence, extensive coaching is vital for them to surpass this struggle.

\subsection{Aim of the Study}

The study aimed to explore the lived experiences of first-time Baccalaureate nursing students in the clinical area. It elucidated their perceptions and feelings with the clinical practice based on their first-ever clinical lived experiences.

\section{Materials and Methods}

\subsection{Design}

This qualitative research utilized phenomenology to explore the lived experiences of first-time Baccalaureate nursing students in the clinical area. Phenomenology elucidates data based on in-depth analysis and personal meaning on the lived human experiences. It is focused on understanding the participants' meaning in their lived experiences (Smith, 2015). This design best captures the participants' facets of human experience in their totality, which appears to be suitable to attain a holistic viewpoint of the nursing students first time exposure in the clinical area.

\subsection{Selection and Site}

Informants were the 18 Baccalaureate nursing students from the male and female campuses of a university in Saudi Arabia who were exposed for the first time in the clinical area. Purposive sampling was used to select the informants and determined based on the following inclusion criteria; nursing students both male and female who are currently enrolled in the Baccalaureate Nursing program, having their current first clinical exposure and enthusiastic to participate in the study

\subsection{Instrument}

A semi-structured interview guide was made by the researchers to elicit participants' perceptions and feelings in their first exposure in the clinical setting. The trustworthiness of the drafted questions was checked by the expert in this field and was revised and enhanced based on the comments and suggestions. Questions in the interview guide were focused on participants' experiences with regards to orientation, coaching of instructors and preceptors, interaction with the client, and collaboration with other health care providers. It also includes the best and worst experiences in the clinical area.

\subsection{Data Collection}

Ethical approval from the university and informed consent from the informants were secured before the data collection. Face-to-face interviews were the main data collection method used which lasted for about 30-45 minutes. Informants were encouraged to talk freely and express their perceptions and feelings on their lived experiences. Finally, the researchers asked for clarifications on the data provided to enhance its validity. The interviews were ended by acknowledging the informants and assured them that the information they provided is treated with the utmost confidentiality. Notes were taken after the interviews were concluded to write down all remarks that may be pertinent in data analysis.

\subsection{Data Analysis}

Researchers interpreted the data using Collaizi's method (as cited by Natividad, 2017). This approach has seven consecutive steps:

1) Reading the interview transcription to grasp the whole idea or opinion of the subjects.

2) Extracting the significant statements or the key responses from the informants.

3) Formulating meaning for significant statements by finding keywords and phrases within each response.

4) Organized formulated meanings into clusters of themes

5) Integrating the findings into an exhaustive description of experiences of first-time nursing students in the clinical practice.

6) Formulate an exhaustive description of the phenomenon into an unequivocal statement of identification. 
7) Validating the findings through member checking and verifying some significant statements by follow-up interviews of some subjects and incorporating changes whenever necessary.

\subsection{Ethical Considerations}

Before the start of the research, ethical approval was obtained from the Review Ethics Committee of the university. Informed consent was drafted with all the information on the study. The informants were given a copy of the informed consent for them to be reminded of the conditions agreed upon. Informants were oriented that their involvement is voluntary and they can withdraw from the study at any time.

With regards to confidentiality and anonymity, the researchers recognized that the interviews can reveal intimate information about their experiences. The informants' descriptions of their experiences were not stored with any identifying labels, and codes were used to replace names. After the analysis of the data, informants were contacted to validate the data they provided.

\subsection{Rigor in Qualitative Research}

Rigor in the study was assured through member-checking. This strengthened the credibility of the results of this qualitative research on the participants' perceptions and feelings by presenting the results, then, seeking feedback from them (Birt, Scott, Cavers, Campbell, \& Walter, 2016; Cypress, 2017)

\section{Results}

Three significant themes with subthemes emerged based on Colaizzi's method of data collection. These include; (1) clinical practice on the first-hand look with subthemes of strange feelings and emotions, communication apprehension, and vague orientation in the unit (2) uncertainties in a new learning environment with subthemes of hesitant to perform nursing procedures, requirements overload, inadequate guidance and supervision by the mentors, and non-compliance on clinical schedule, and; (3) nursing as a life-changing experience with the subthemes of sympathetic understanding, sense of fulfillment and transformative experience.

Theme 1. Clinical practice on the first-hand look. Informants viewed their first clinical practice as entirely different from their day to day activities inside the university. Interacting with the real patient in the clinical area for the first time is quite overwhelming for them.

Subtheme 1. Strange feelings and emotions. Exposure in the clinical area leads to mixed feelings as the informants shared during the interview. The sight of the environment makes them feel worried at the same time nervous This is supported by the informants' significant statements:

F1 - "Different from the lab... at the first I feel strange with the place... then from the patient... you deal with the real patient... move... talk...interview them...it's different."

F2 - "I exposed to many cultures. At first visit with my patient...I feel afraid for the first time."

F4 - "I feel quite nervous... I am more good in theory than in practice."

M5 - "At first I am fearful and so nervous talking to real patients... I am afraid, I might commit mistakes."

Subtheme 2. Communication Apprehension. Talking with the real patient is quite hard for the informants. Conversation with them is different from the usual things they are doing during the performance of the procedure in the skills laboratory with their classmates are the ones who act as their patients. The participants alluded as follows:

F1 - "I have a problem in communicating with the patient...It's hard to communicate with the patient...I am very shy..."

F8 - "Scared to talk with them... but I have this enthusiasm with getting information to my patient ... patient is nice and collaborative."

M2 - "A little bit nervous... hesitant to start the conversation."

M4 - "I feel nervous when starting to talk with my patient.... a little bit of tachycardia..."

Subtheme 3. Vague orientation in the unit. The informants voiced out that they need a thorough orientation since they did not know yet the who, what, where, and when of clinical practice. They need guidance from the clinical instructors/ professors and preceptors to boost their enthusiasm to be engaged with their very first clinical experience. Four of the informants stated the following:

F3 - "We are the ones who look for the different areas in the unit.. like medication room."

F4 - "No one orient us with the clinical set up." 
M3 - "We did not have an orientation on the first day of hands-on training..."

M6 - "Not all of them oriented us... we do it on our own.."

Theme 2. Uncertainties in a new learning environment. Since it is the first time of nursing students in the clinical practice, they have this apprehension of doing things. They are fearful of committing mistakes even in performing simple nursing skills.

Subtheme 1. Hesitant to perform nursing procedures. Though the nursing skills were taught in the skills laboratory before the students' clinical exposure, still informants were uneasy when doing the procedure with their patients. Hesitancy is evident in the following statements of the informants:

F1 - "With my first procedure... it's quite too difficult to implement... I am trembling when I do my first injection. "

F2 - "I am quite hesitant and nervous when I assist the doctor doing the wound care... but as I go along with it... I feel comfortable."

F4 - "I think it is my problem... I am a little bit anxious when I am doing my procedure, especially that my patient has Down syndrome... I am not that confident”

M6 - "Fear of doing activities... I have this feeling that I might hurt my patient..."

M11 - "At first it was difficult... The patient keeps asking questions...so you have to be patient...It takes a lot of courage to do I with the real patient..."

Subtheme 2. Requirements overload. Requirements are part of the clinical practice but for the informants, too much of this leads to a burden on their part. For them, they tend to do paper works rather than performing bedside care and nursing skills. Sharing of the informants are the following:

F14 - "If the college continues to focus on paper, training is useless. The time allocated for writing is supposed to be less than the practical skills of the students. Some students graduated with us and do not know how to give the injections."

F16 - "Most of the time we spend filing paperwork to take the grades without the actual practice as iffield training was found to fill papers by reading files only."

M3 - "There was no application, just writing papers..."

M5- "Most of the training time went in writing and the students occupied the basic goal, namely the actual training and practical application on the ground for what was studied at the college, attendance early from 8 am and morning 12.30 in the afternoon.

Subtheme 3. Non-compliance with scheduled clinical hours.

F9 - "Time wasn't enough... we started at 9 am because the bus is late and the doctors are not yet there, the schedule is confusing."

F10 - "We came late in the clinical area... the bus is late...

M2 - "The training time varies according to the instructor and we finish the training at approximately noon."

M3 - "Varies according to the teacher but often start 8 and we leave 12noon because they said that the bus will pick up other students from other hospitals and we have a half-hour break."

Subtheme 4. Inadequate guidance and supervision by the mentors.

F2 - "Other nurses don't want us to help us because they think we are not that smart."

M3 - "Some of the professors attend the first day only while others sit with us and help us all the time..."

M5 - Some of them just prepare the students and go and will not return as the students know his way to wait for... some do not come to the hospital final and inform the management of training or nursing prepare students on behalf of him or the leader of the group with us and remain throughout the day do not work for you."

Theme 3. Nursing is a life-changing experience. The experience of being with the real patient made the nursing students realized the true meaning of Nursing not only as their future job but most importantly how it made them become a compassionate person they did not expect them to be.

Subtheme 1. Sympathetic understanding. Being with the patient makes the informants became sensitive and more concerned with others. They recognize what the patients feel as they interact with them. Informants shared the following statements:

F1 - "Every time I go home I feel sad about the patient.. some patients cry and feel pain and complain to you... 
especially children... and you cannot do something about it... I am also a mother that is why... The patient is different from the doll... “"

F2 - "I feel sad about the patient especially when they are in pain... when they are relieved with the medication I feel relieved also."

F10 - "At first I am very disappointed... After my exposure, I went to my mother and cried because I feel what my client feels... I feel sad about my patient..."

Subtheme 2. Sense of fulfillment. Doing little things with compassion is an achievement for the informants. Listening and being attentive with their patients makes them feel that they are needed and valued. Four informants are glad when they shared the following:

F1 - "Talking with the patient and hearing their concerns... It seems that they have full trust with us."

F4 - "Interacting with the patient is enjoyable for me.. as if they treat me as I am a real staff nurse. They vent out their feelings towards their illness."

F11 - "The most enjoyable one... it was surprising to have this feeling helping patient...Collaborating with doctors."

M5 - "Practical application of what we learned in the college, which contributes to the retention of more information. I learned a lot."

Subtheme 3. Transformative experience. Caring for the needy and sick patients provide a treasurable experience for the participants. The positive outlook that they gain from their first clinical experience leads to encouragement and inspiration for them to pursue their chosen profession. The following excerpts illustrate the point:

F3 - "When I am not having my first clinical practice I love nursing... but after my very first experience I love nursing more... it is really life-changing... my family always asking me about lab test.. and looking at me as if I am a full pledge nurse..."

F8 - "There is a nurse who told me that why did you choose Nursing... it's not good... because of this experience... I don't want to be like them."

F11 - "A lot... you do not know how much... you look the world in a different way...I see things that make me more thankful for myself... It made me feel think a lot about life...It makes me feel that I need to be stronger to help someone who needed me... I do not want to experience the patient sufferings...so I need to be healthy... When I am doing things with the patient... I am thinking that it's me... so I need to do my best..."

\section{Discussion}

The core of the study was established by extracting the participants' verbalizations from the interview to create the meaning of their lived experiences. Upon exploring their lived experiences, three themes emerged with the core of the study as "metamorphosis". The participants' meaning elucidated "metamorphosis" experiences into first-hand look in the clinical practice, uncertainties with the new learning environment, and nursing as a life-changing experience.

Nursing students are overwhelmed with the glimpse of the clinical setting since they are a novice in the clinical practice. A sudden change from the usual activities in the skills laboratories to the real world of nursing practice makes them feel that they are somewhat awkward with the clinical environment. The reality that they are dealing with the actual client is a challenge. That is why the guidance of the clinical mentors and preceptors must be of great consideration. Lack of support from nursing educators in the application of practical skills could affect students' opportunities for experiential learning. They must orientate the students before the beginning of clinical placements to lessen the apprehension and anxiety in a real-life clinical situation (Lee \& Yang, 2019). Student orientation enhances motivation and engagement towards the nursing program hence it will also develop a passionate desire to become a nurse (Ten Hoeve, Castelein, S. Jansen, W. Jansen, \& Roodbol, 2017). Clinical orientation is one of the important pillars of students' engagement in learning and this will guide them on how they will adapt to this new environment. Likewise, the support and supervision from the clinical instructors and preceptors are needed by the nursing students as they explore the field of clinical practice (Atakro et al., 2019; Lapeña-Moñux, Cibanal-Juan, Orts-Cortés, Maciá-Soler, \& Palacios-Ceña, 2016).

Socialization strategy is beneficial for the students to adapt completely to the clinical learning environment. The role modeling of the clinical instructors and preceptors influences the confidence level of nursing students in the clinical practice (Baraz, Memarian, \& Vanaki, 2015; Houghton, 2014). Nursing students wanted to allocate more time in clinical practice. Ineffectual assistance from the staff nurses and minimal guidance from clinical instructors 
hinders the students' learning opportunities in the clinical practice (Kamphinda \& Chilemba, 2019). The number of hours allotted in clinical learning is not enough considering some predicaments like; late arrival of service vehicle; tardiness of some clinical instructors and early dismissal in the clinical area.

Students are expecting that clinical instructors will be the ones to facilitate their participation in clinical nursing activities, but it seldom happened. Henceforth, staff nurses should also provide clear directions to students whenever rendering nursing care (Bigdeli et al., 2015).

It is a common scenario that nurses and doctors prioritize medical interns rather than other health sciences students. This scenario creates a negative effect in which the nursing students may view the clinical environment as ineffective for learning opportunities (Farzi, Shahriari, \& Farzi, 2018). Hence, an inter-professional partnership among nurse educators and clinical staff must be taken into consideration to enhance students' motivation thereby attaining a better learning experience.

It can be viewed that nursing students encountered difficulties in clinical practice, which originated from non-supporting instructors and clinical environment factors. However, the students themselves are also a factor in their difficulties which is evident in their inadequate self-confidence, and the lack of role modeling among clinical instructors and preceptors added on to this problem (Drateru, 2019). These difficulties produce anxiety that hinders the students from optimizing their learning in the clinical practice.

Moreover, the clinical requirements became a burden among nursing students (Galvin, Suominen, Morgan, O'Connell, \& Smith, 2015). Assignment and clinical workloads were the perceived source of stress of the students in clinical training (Alsaqri, 2017; Hamaideh, Al-Omari, \& Al-Modallal, 2017; Ismail, 2017). Due to this burden, students perceived the clinical training as merely complying with the paperwork requirements rather than honing their nursing skills. In that way, more attention must be given to actual training and minimize paper works so that students will be able to focus on rendering patient care (Al-Zayyat \& Al-Gamal, 2014).

Aside from it, the experienced of 'being criticized by teachers' and 'fear of making errors' make the students feel pressured in their clinical practice (Bahadır-Yılmaz, 2016). If the students face such predicaments, it is unusual for them to focus on the tasks that are supposed to be done to enhance their skills and became equipped for their future work. By this means, self-directed learning paths must be established before the students' clinical placement to prepare them and enhance their learning opportunities. This will also enable them to set their goals and find ways to work on it. (Moquin, Seneviratne, \& Venturato, 2018). Additionally, the evaluation in the clinical area must be done as it fosters positive and constructive feedback among students. Conducting pre-conference and post-conference in the clinical practice motivates the students to be fully involved in acquiring further knowledge and skills in the clinical practice (Yeldon et al., 2018). In the end, open communication between the clinical instructor and student provide meaningful learning in their clinical placement such as an opportunity to witness complex clinical cases and utilized advanced medical equipment and devices in implementing nursing care (Atakro et al., 2019).

Recognizing what others feel is substantial learning for the students. Nursing educators contribute a lot in promoting meaning in life to nursing students through proper guidance and motivation, so in that way, it creates a positive outlook towards their profession itself. (Tsai et al., 2018). The experience of caring for a client with 'cognitive and physical limitations' resulted in a completely changed perspective of caring, compassion, and respect indicative of rewarding, and life-changing experience (Brown \& Bright, 2017).

Nursing students experience transition, in which stress and anxiety are not an excuse as they are exposed to the challenging clinical environment. Yet, the sequel of this transition is the acquisition of new knowledge, enhancement and development of skills, and effective transformation. Understanding this, nurse educators can devise an effective clinical training program that will progress students' clinical learning practices to produce caring and competent nurses of the future (Hart \& Swenty, 2016).

To improve the clinical experience, the Evidence-Based Practice (EBP) Program can be utilized in the clinical learning environment. Its inclusion in the pedagogical nursing curriculum will promote the enhancement of competency of undergraduate nursing students (Kim, Gu, \& Chang, 2019). Equally, a Preceptorship program can be an effective tool in improving nursing students' self-efficacy as being influenced by preceptors 'teaching experience, personal qualities, interaction with students, and professional development' (Rambod, Sharif, \& Khademian, 2018). Partnership and collaboration between faculty of nursing colleges and staff of affiliating institutions matter a lot, as Woo and $\mathrm{Li}$ (2020) concluded that "Involvement" would complement "Personalization" and "Task orientation" and finally holistic clinical learning experience can be achieved.

By this means, it is important to note that instructional design must be reviewed, clinical orientation before the start 
of the program must be conducted which is deemed to be the weakness of the clinical program, thus, access to counseling and support services must be considered. An evaluation must be continuously done to discern how the students 'fit in' with the clinical practice. Recognizing this through the lens of novice student nurses in the clinical learning environment can create a better program that enhances successful experiential learning.

\section{Conclusion and Recommendations}

Nursing students who had their first-ever exposure to clinical practice had various experiences both positive and negative. They have unusual feelings in the clinical learning environment which were heightened by their hesitancy to collaborate with staff nurses as they feel that they have an inadequacy in doing nursing procedures. Insufficient time in the clinical area and inadequate guidance from instructors contributed to their feelings of reluctance. Contrariwise, these novice student nurses surpass these difficulties and were able to appreciate the real essence of "being a nurse" in the nursing profession.

The Nursing College must review the clinical program and must emphasize comprehensive orientation before students' exposure to clinical practice. There is a need to conduct evaluation and monitoring in the clinical area for both nurse educators and clinical preceptors. Proper coordination and collaboration with the affiliating institutions must be done to ensure success in clinical learning. Clinical portfolio with learning journals must be monitored to evaluate students' transitions in clinical practice.

\section{Competing Interests Statement}

The authors declare that there are no competing or potential conflicts of interest.

\section{References}

Al Saqri, S. H. (2017). Stressors and coping strategies of the Saudi nursing students in the clinical training: a cross-sectional study. Education Research International. https://doi.org/10.1155/2017/4018470

Alzayyat, A., \& Al-Gamal, E. (2014). A review of the literature regarding stress among nursing students during their clinical education. International Nursing Review, 61(3), 406-415. https://doi.org/10.1111/inr.12114

Atakro, C. A., Armah, E., Menlah, A., Garti, I., Addo, S. B., Adatara, P., \& Boni, G. S. (2019). Clinical placement experiences by undergraduate nursing students in selected teaching hospitals in Ghana. BMC Nursing, 18, 1 . https://doi.org/10.1186/s12912-018-0325-8

Bahadır-Yılmaz, E. (2016). Academic and clinical stress, stress resources and ways of coping among Turkish first-year nursing students in their first clinical practice. Kontakt, 18(3), e145-e151. https://doi.org/10.1016/j.kontakt.2016.08.001

Baraz, S., Memarian, R., \& Vanaki, Z. (2015). Learning challenges of nursing students in clinical environments: A qualitative study in Iran. Journal of Education and Health Promotion, 4. https://doi.org/10.4103/2277-9531.162345

Bigdeli, S., Pakpour, V., Aalaa, M., Shekarabi, R., Sanjari, M., Haghani, H., \& Mehrdad, N. (2015). Clinical learning environments (actual and expected): perceptions of Iran University of Medical Sciences nursing students. Medical Journal of the Islamic Republic of Iran, 29, 173.

Birt, L., Scott, S., Cavers, D., Campbell, C., \& Walter, F. (2016). Member checking: a tool to enhance trustworthiness or merely a nod to validation? Qualitative Health Research, 26(13), 1802-1811. https://doi.org/10.1177/1049732316654870

Brown, K. M., \& Bright, L. M. (2017). Teaching caring and competence: Student transformation during an older adult focused service-learning course. Nurse Education in Practice, 27, 29-35. https://doi.org/10.1016/j.nepr.2017.08.013

Cypress B. S. (2017). Rigor or Reliability and Validity in Qualitative Research: Perspectives, Strategies, Reconceptualization, and Recommendations. Dimensions of Critical Care Nursing: DCCN, 36(4), 253-263. https://doi.org/10.1097/DCC.0000000000000253

Drateru, K. C. (2019). Challenges Experienced by Student Nurses During Skill Acquisition at The Clinical Area. Nur Primary Care, 3(3), 1-4. Texila American University, Uganda. https://doi.org/10.33425/2639-9474.1104

Farzi, S., Shahriari, M., \& Farzi, S. (2018). Exploring the challenges of clinical education in nursing and strategies to improve it: A qualitative study. Journal of Education and Health Promotion, 7, 115. https://doi.org/10.4103/jehp.jehp_169_17 
Galvin, J., Suominen, E., Morgan, C., O’Connell, E. J., \& Smith, A. P. (2015). Mental health nursing students' experiences of stress during training: a thematic analysis of qualitative interviews. Journal of Psychiatric and Mental Health Nursing, 22(10), 773-783. https://doi.org/10.1111/jpm.12273

Hamaideh, S. H., Al-Omari, H., \& Al-Modallal, H. (2017). Nursing students' perceived stress and coping behaviors in clinical training in Saudi Arabia. Journal of Mental Health (Abingdon, England), 26(3), $197-203$. https://doi.org/10.3109/09638237.2016.1139067

Hart, J. A., \& Swenty, C. F. (2016). Understanding Transitions to Promote Student Success: A Concept Analysis. Nursing Forum, 51(3), 180-185. https://doi.org/10.1111/nuf.12136

Houghton C. E. (2014). Newcomer adaptation: a lens through which to understand how nursing students fit in with the real world of practice. Journal of Clinical Nursing, 23(15-16), 2367-2375. https://doi.org/10.1111/jocn.12451

Ismail, S. (2017). Perceived clinical stressors among Saudi nursing students. Open Journal of Nursing, 7(04), 463. https://doi.org/10.4236/ojn.2017.74036

Kamphinda, S., \& Chilemba, E. B. (2019). Clinical supervision and support: Perspectives of undergraduate nursing students on their clinical learning environment in Malawi. Curationis, 42(1), e1-e10. https://doi.org/10.4102/curationis.v42i1.1812

Kim, J. S., Gu, M. O., \& Chang, H. (2019). Effects of an evidence-based practice education program using multifaceted interventions: a quasi-experimental study with undergraduate nursing students. BMC Medical Education, 19(1), 71. https://doi.org/10.1186/s12909-019-1501-6

Lapeña-Moñux, Y. R., Cibanal-Juan, L., Orts-Cortés, M. I., Maciá-Soler, M. L., \& Palacios-Ceña, D. (2016). Nurses' experiences working with nursing students in a hospital: a phenomenological enquiry. Revista Latino-americana de Enfermagem, 24. https://doi.org/10.1590/1518-8345.1242.2788

Lee, J. J., \& Yang, S. C. (2019). Professional socialisation of nursing students in a collectivist culture: a qualitative study. BMC Medical Education, 19(1), 254. https://doi.org/10.1186/s12909-019-1690-z

Moquin, H., Seneviratne, C., \& Venturato, L. (2018). From apprehension to advocacy: a qualitative study of undergraduate nursing student experience in clinical placement in residential aged care. BMC Nursing, 17,8 . https://doi.org/10.1186/s12912-018-0277-z

Natividad, M. J. B. (2017). Battle and Fettle of Chronically Middle-Aged Adults: Basis for Eclectic Therapy. Asia Pacific Journal of Multidisciplinary Research, 5(2), 102-113. https://doi.org/10.1097/NCI.0b013e3181

Rambod, M., Sharif, F., \& Khademian, Z. (2018). The Impact of the Preceptorship Program on Self-efficacy and Learning Outcomes in Nursing Students. Iranian Journal of Nursing and Midwifery Research, 23(6), 444-449. https://doi.org/10.4103/ijnmr.IJNMR_67_17

Smith, J. A. (Ed.). (2015). Qualitative psychology: A practical guide to research methods. Sage.

Sun, F. K., Long, A., Tseng, Y. S., Huang, H. M., You, J. H., \& Chiang, C. Y. (2016). Undergraduate student nurses' lived experiences of anxiety during their first clinical practicum: A phenomenological study. Nurse Education Today, 37, 21-26. https://doi.org/10.1016/j.nedt.2015.11.001

Ten Hoeve, Y., Castelein, S., Jansen, W. S., Jansen, G. J., \& Roodbol, P. F. (2017). Nursing students' changing orientation and attitudes towards nursing during education: A two-year longitudinal study. Nurse Education Today, 48, 19-24. https://doi.org/10.1016/j.nedt.2016.09.009

Tsai, F. J., Chen, C. Y., Yeh, G. L., Hu, Y. J., Tseng, C. C., \& Chen, S. C. (2018). Nursing students' relationships among meaning in life, well-being, and positive beliefs: A cross-sectional survey study. Medicine, 97(42), e12914. https://doi.org/10.1097/MD.0000000000012914

Turner, K., \& McCarthy, V. L. (2017). Stress and anxiety among nursing students: A review of intervention strategies in literature between 2009 and 2015. Nurse Education in Practice, 22, 21-29. https://doi.org/10.1016/j.nepr.2016.11.002

Woo, M., \& Li, W. (2020). Nursing students' views and satisfaction of their clinical learning environment in Singapore. Nursing Open, 7(6), 1909-1919. https://doi.org/10.1002/nop2.581

Yeldon, J., Wilson, R., Laferrière, J., Arseneau, G., Gu, BSc, S., Hall, M., ... \& Mori, B. (2018). Let's talk about the talk: Exploring the experience of discussing student performance at the mid-and final points of the clinical internship. Physiotherapy Canada, 70(3), 240-248. https://doi.org/10.3138/ptc.2016-96 


\section{Copyrights}

Copyright for this article is retained by the author(s), with first publication rights granted to the journal.

This is an open-access article distributed under the terms and conditions of the Creative Commons Attribution license (http://creativecommons.org/licenses/by/4.0/). 